\title{
MEDIDAS SOCIOEDUCATIVAS: A (IN)EFICÁCIA DA APLICAÇÃO
}

Olivie Samuel Paião, Renata Poloni Sanches

Universidade do Oeste Paulista - UNOESTE, Curso de Direito, Presidente Prudente/SP. E--mail: oliviesamuel@hotmail.com

\section{RESUMO}

O Estatuto da Criança e do Adolescente (ECA) recebe muitas críticas, especialmente por não conhecer o real sentindo da aplicação das medidas socioeducativas aos atos infracionais praticados por adolescentes. Em um rol taxativo, o ECA contém medidas que devem ser aplicadas aos menores infratores, não aplicadas como punição, mas de conscientização pelo fato praticado e no intuito de reintegração social. Nesta abordagem o objetivo deste estudo é demonstrar que a aplicação das medidas socioeducativas do ECA são viáveis aos adolescentes, excluindo a aplicação do código penal. Utilizando metodologia dedutiva bibliográfica, os resultados apresentados são congruentes a uma eficácia da aplicação do ECA num trabalho conjunto entre Estado e sociedade. Palavras-chave:Estatuto da Criança e do Adolescente, medidas socioeducativas, atos infracionais, legislação especial, menores infratores.

\section{EDUCATIONAL MEASURES:THE (IN)APPLICATION OF EFFECTIVENESS}

\begin{abstract}
The Statute of Children and Adolescents (ECA) receives a lot of criticism, especially not knowing the real feeling and implementation of social and educational measures to illegal acts committed by adolescents. In an exhaustive list ECA contains measures to be applied to juvenile offenders, not applied as punishment, but awareness of the fact practiced and social reintegration purposes. In this approach the aim of this study is to demonstrate that the application of educational measures the ECA are viable adolescents, excluding the application of the penal code. Using literature deductive methodology, presented results are congruent to an ECA application effectiveness in a joint effort between state and society.

Keywords: Children and Adolescents' statute, social and educational measures,illegal acts, special legislation, child offenders.
\end{abstract}




\section{INTRODUÇÃO}

Muitas opiniões cercam como devem ser feitas as correções dos atos considerados delituosos praticados por menores de idade que, no texto legal do Código Penal, são consideráveis inimputáveis, ou seja, não são submetidos ao mesmo tratamento que de pessoas maiores de idade e com capacidade plena que cometeram crimes.

De acordo com a evolução relatada na obra Histórico do Atendimento das Medidas Socioeducativas em Meio Aberto (FEBEM; ADMA, 2007, p. 02):

O Código Criminal do Império, em 1830, fixou a responsabilidade penal em 14 anos, e à casa de recolhimento aqueles que tinham discernimento de seus atos, sem limite inferior. No primeiro código penal da República (1890), a idade prefixou-se em 09 anos, elevando-se a 14 com o advento da Lei orçamentária que autorizou a organização do serviço de assistência e proteção à infância abandonada e delinquente. Em 1927 teve o decreto $n$ o 17.943-A, que programou o primeiro código de menores, consolidando direitos da criança e do adolescente no Brasil. Após alguns anos, entrou em vigor o Código Penal de 1940, nosso atual código, que fixou a responsabilidade penal em 18 anos, com atenuantes à faixa de 18 a 21 anos. Por fim, em 13 de julho de 1990 houve a promulgação do Estatuto da Criança e do Adolescente.

Hoje, a forma adotada é corrigir e reeducar os menores infratores por intermédio do Estatuto da Criança e do Adolescente (ECA), Lei no 8.609/90, embasando-se nas medidas socioeducativas elencadas no texto legal que serão abordadas no decorrer deste artigo.

A finalidade do presente artigo é demonstrar que as medidas socioeducativas devem ser aplicadas nas regras contidas do Estatuto da Criança e do Adolescente, não perdendo seu objetivo principal de orientar e corrigir o adolescente infrator, reinserindo-o na sociedade em que vive.

\section{METODOLOGIA}

Utilizando-se do método denominado dedutivo, de forma lógica, tem-se uma teoria conhecida como verdadeira ou indiscutível, pois tal método resume-se em respaldar uma conclusão sustentada por premissas preexistentes consideradas verdadeiras, "no método dedutivo se procura a todo custo confirmar a hipótese" (GIL, 2008, p. 12). Assim sendo, não há "graduações intermediárias", pois a dedução permite, por meio da lógica, chegar a uma conclusão formal, não deixando margens à dúvida sobre sua veracidade (MARCONI; LAKATOS, 2003, p.92). Prima-se por análise lógico-racional, utilizando-se, para sustentar a presente abordagem, da historicidade do direito, da legislação em questão, além de jurisprudências, revistas do direito, doutrina jurídica e afins, revistas populares, artigos publicados e jornais que se fizeram úteis ao estudo do tema.

\section{RESULTADOS}

É nos momentos mais acalorados e posteriores a um fato alarmante e de risco social praticado por um menor que os favoráveis à redução da maioridade se manifestam implantando suas ideias. Aproveitando-se do clima de medo, do sentimento de impunidade e de insegurança, dissipam que as medidas existentes não são suficientes e que, por esse motivo, o fato delituoso veio a existir.

Afirmam que o ato cometido por um menor não o levará para cadeia e dessa forma, consequentemente, ele continuará a praticar os mesmos atos. Embasando-se nesse argumento, disseminam que a solução para todo o problema é simplesmente reduzir a idade penal. 
Contrapondo-se a essa ideia, o médico, cientista e escritor Dr. Dráuzio Varella (VARELLA, 2015) afirmou que tratar o menor da mesma forma com que se trata um maior é um erro, descrevendo o seguinte:

Pegar esse menino e jogá-lo numa penitenciária no meio de bandidos de longa carreira no crime não é uma medida inteligente, porque ele vai chegar na cadeia, garotão ainda, no meio daqueles adultos, vai se sentir desamparado, com medo, medo de ser estuprado, medo de morrer na mão dos adversários. E o que ele vai fazer? Ele vai se juntar a uma das facções que dominam os presídios, aí ele 'tá' protegido e a família passa a receber uma cesta básica, paga pela facção. A mãe poderá visita-lo e ir de ônibus para o interior transportada 'as custas' dos recursos da facção. Só que o dia que ele sair da cadeia, e ele um dia sairá, ele vai sair absolutamente comprometido com o crime e não terá nenhuma chance de sair fora desse mundo nem que ele queira.

A verdade destes fatos é mascarada ao se afirmar que os adolescentes ficam impunes, pois existe a aplicação de medidas socioeducativas a fim de coibir a reincidência e fazer com que 0 jovem se integre à sociedade a que pertence.

O artigo 112 do ECA, em um rol taxativo, descreve as medidas a serem aplicadas aos menores, fazendo-nos entender, automaticamente, que o adolescente responde socialmente por seus atos quando da prática de uma infração.

Após a infração, o adolescente é encaminhado à delegacia especializada (Delegacia da Criança e do Adolescente-DCA), quando existentes, onde é lavrado o boletim do ocorrido, que, encaminhando ao Poder Judiciário, este reconhecerá (ou não) a prática infracional, com o encaminhamento do adolescente ao sistema fechado ou semiaberto (Fundação Casa) ou ao sistema aberto (liberdade assistida e prestação de serviços à comunidade), com atividades desenvolvidas pelo CREAS (Centro de Referência Especializado da Assistência Social) nos municípios, conforme orientação do SINASE.

O caráter das medidas não é, intrinsecamente, punir. LIBERATI (2000, p.82) afirma que "tal medida, antes de ser punitiva, pretende, de forma pedagógica, orientar o adolescente a respeitar os bens e patrimônios de seus semelhantes."

Logo, as medidas têm finalidade de reintegração do adolescente, conforme o artigo "Medidas Socio-educativas para Jovens em Situação de Risco [...]" (2007, p.13), publicado pelo estado do Ceará. Tal artigo descreve que as referidas medidas “(...) são, portanto, deveres que juízes da infância e da juventude impõem aos adolescentes que cometem ato infracional. 0 objetivo não é a punição, mas a efetivação de meios para reeducá-los".

Neste sentido, poderá haver aplicação pelo juiz de uma das sanções previstas do rol do artigo 112, ECA, quais sejam: I. advertência; II. obrigação de reparar o dano; III. prestação de serviço à comunidade; IV. liberdade assistida; V. inserção ao regime de semiliberdade; VI. internação em estabelecimento educativo; VII. qualquer uma das previstas no artigo 101, I ao VI.

Assim, de forma sucinta, as medidas socioeducativas aplicáveis são:

a) Advertência: esta tem como essência, advertir o menor e seus responsáveis, em forma de um conselho, a não praticar os atos considerados infracionais e delituosos. A intenção é mostrar que com a prática de tais atos seu futuro pode ser prejudicado, se transformando em dependente do crime, e que há outros meios de ter o que se busca;

b) Obrigação de reparar o dano: Seria uma forma de o menor recompor aquilo que danificou, o que, de certa forma, o levará a dar valor aos bens e patrimônios que deteriorou. Embasando-se no que Liberati dispôs, seria uma forma pedagógica de o adolescente respeitar os 
bens de outrem. Quando esta for impossível, outra medida será tomada, desde que seja direcionada ao menor, para que a lei atinja, então, seu objetivo e cumpra seu caráter educador;

c) Prestação de serviço à comunidade: São tarefas sem remuneração que o menor deve prestar a favor da sociedade (em entidades assistenciais, hospitais, escolas ou estabelecimentos correlatos), não excedendo 06 meses, 08 horas diárias e não interferindo em seu horário escolar e jornada de trabalho, caso o menor tenha uma ocupação.

d) Liberdade assistida: Equipes multidisciplinares auxiliam, orientam e acompanham o adolescente por certo período, com prazo mínimo de 06 meses. Neste caso, é encargo do orientador/equipe direcioná-lo à escola, mercado de trabalho, promoção social, etc.

e) Inserção ao regime de semiliberdade: medidas de caráter coercitivo, mas sem perder o caráter educador, tem como foco vincular o jovem a uma unidade especial, retirando, momentaneamente, sua liberdade. Entretanto, o jovem pode ter atividades externas, sendo obrigatórias as relacionadas à profissionalização e à escolarização.

f) Internação em estabelecimento educativo: tem caráter de medida privativa de liberdade. Não excederá a três anos. Geralmente aplica-se aos reincidentes e aos menores que praticam atos mais violentos. Esta medida deve ser breve e excepcional, fazendo-se uma avaliação semestral do adolescente internado. É aplicada de maneira equilibrada e sensata, mas não sendo tão branda a ponto de insuflar no jovem algum sentimento de impunidade.

Vale ressaltar que as medidas socioeducativas têm elucidação própria a luz dos artigos 115 ao 125 do ECA.

É correto dizer que há falhas na aplicação das medidas socioeducativas, mas não se trata de falhas estruturais e sim no que se refere à aplicação correta das mesmas. O ECA prevê normas que são eficientes, porém, como em todos os outros sistemas que existem, é necessário dar a devida atenção, não se resguardar na omissão, o que vale tanto para a sociedade, envolvendo aqui todos os que a constituem, quanto para as decisões políticas.

A inércia não gera frutos. Pelo contrário, deixa de produzi-los. E, talvez, o erro maior seja tapar os ouvidos e os olhos e apenas dizer que se quer melhorias, não procurando resolver a raiz do problema, mas apenas podando os galhos que incomodam.

Depreende-se neste estudo que modificar a maioridade penal a fim de aplicação de normas penais a adolescentes que ainda estão em formação é um erro. O que se faz necessário é a efetivação na aplicação das normas contidas no ECA, reestruturando-se os serviços de inserção do adolescente à sua realidade.

\section{DISCUSSÃO}

Segundo a Constituição Federal de 1988, pela redação no artigo 227, o amparo às crianças e adolescentes deve seguir a norma referida, que assim se dispõe (BRASIL, 1988):

É dever da família, da sociedade e do Estado assegurar à criança, ao adolescente e ao jovem, com absoluta prioridade, o direito à vida, à saúde, à alimentação, à educação, ao lazer, à profissionalização, à cultura, à dignidade, ao respeito, à liberdade e à convivência familiar e comunitária, além de colocá-los a salvo de toda forma de negligência, discriminação, exploração, violência, crueldade e opressão.

Não é preciso uma análise aprofundada para descobrir que esta disposição foi e é uma das mais falhas da Constituição Federal/88, haja vista que constantemente a população se depara com crianças abandonadas, solitárias, sem um emprego decente, sem alimento na mesa, sem família, sem cultura, sem escola, sem educação, às margens de uma vida indigna, seja na prostituição ou na marginalidade infantil. Para Isabela e Pedro (HENRIQUES; HARTUNG, 2013), o 
artigo 227 da Constituição tem grande relevância jurídica, o que descrevem nas seguintes palavras:

Dentro do sistema de normas da Constituição Federal, não há nenhuma outra determinação tão forte e expressa no sentido da proteção de direitos. $O$ art. 227 coloca a criança como foco central de todas as preocupações constitucionais, determinando, ao menos no plano deontológico, que seus direitos e interesses devem ser observados em $1^{\circ}$ lugar, antes de qualquer outro interesse ou preocupação.

A criminalidade cresceu espantosamente e o sentimento que domina a maior parte das pessoas é o da impunidade. Logo, ao se perguntar ao homem médio se ele quer que o bombeiro, o escrivão ou até mesmo o juiz ajudem a rondar suas casas, a protegê-los dos maus feitores e a combater todos os delitos com as próprias mãos, além de auxiliar nas investigações, sua resposta será, certamente, sim.

O único desejo a se superpor sobre quaisquer outros é o da segurança, seja de sua vida, de sua família ou de seu patrimônio, não levando em consideração as atribuições e esfera de competência de cada autoridade, seja ela administrativa ou judiciária.

Atualmente, o código penal conclui que os menores, bem como os doentes mentais, são inimputáveis, conforme o disposto nos artigos 26 e 27, título III, do referido código, ou seja, a estes não se aplicam a mesma punição que para um homem maior de idade e capaz de responder por seus atos. Neste sentido, o artigo 27 do CP afirma que os menores de 18 (dezoito) anos são penalmente inimputáveis, ficando sujeitos às normas estabelecidas na legislação especial.

Os menores recebem um tratamento diferenciado, sendo regido pelo ECA (Estatuto da Criança e do Adolescente), que se responsabiliza por aplicar medidas socioeducativas para corrigir os atos infracionais dos menores infratores, afinal "pretendem ser medidas de reintegração, de inclusão de natureza educativa e não punitivas" (CEARA, 2007, p. 07).

Assim, ato infracional pode ser definido como todo:

Ato condenável, de desrespeito às leis, à ordem pública, aos direitos dos cidadãos ou ao patrimônio, cometido por crianças ou adolescentes. Só há ato infracional se àquela conduta corresponder uma hipótese legal que determine sanções ao seu autor. (Disponível em: https://issuu.com/mauricioaraya/docs/guia_sobre_medidas_s ocioeducativas, acesso em 15 Set. 2016).

No caso de ato infracional cometido por crianças (até 12 anos), aplicam-se as medidas de proteção. Nesse caso, o órgão responsável pelo atendimento é o Conselho Tutelar.

$\mathrm{O}$ ato infracional cometido por adolescentes (maiores de 12 anos até 18 incompletos) devem ser apurados pela Delegacia da Criança e do Adolescente, quando existentes, a quem cabe encaminhar o caso ao Promotor de Justiça, que poderá aplicar, através do Poder Judiciário, uma das medidas sócio-educativas previstas no Estatuto da Criança e do Adolescente da Criança e do Adolescente, Lei 8.069/90, doravante ECA.

Por tratarem os atos cometidos por menores com uma nomenclatura diferente e medidas corretivas diferenciadas, muitas opiniões fuzilam o atual sistema correcional, com o argumento de que isto é a forma de dar a um delinquente aval para reincidência, dando brecha à impunidade.

A partir do momento que não se enxerga a distinção entre impunidade e imputabilidade, a nítida ignorância se manifesta, no real significado da palavra, levando a opinião pública para um caminho completamente obscuro e ilegal: a redução da maioridade penal.

Esta opinião se principia, em alguns, na falta de conhecimento dos meios e instrumentos utilizados pelo ECA; em outros, na indução de pessoas menos informadas ou que já passaram por 
situações cautelosas, ou até mesmo por quem quer oferecer uma solução, mas não sabe o que dizer.

Antônio Carlos $\operatorname{Costa}^{1}$ (1991, p. 49) discursou certa vez que "vomitam aquilo do qual não se alimentaram" ${ }^{2}$, ou seja, opinam soluções sem saberem as causas do problema.

As medidas socioeducativas são, sim, eficazes, mas quem procura saber os bons resultados e fins exitosos que estas alcançaram? Esforçados e pouquíssimos interessados. Não há divulgação da eficácia alcançada pela aplicação das medidas socioeducativas aos adolescentes, divulgando-se, tão somente, o ato infracional cometido no intuito da desmoralização e irresponsabilidade, advinda daquele adolescente, levantando-se ao questionamento da alteração da maioridade penal.

O Código Penal têm medidas satisfatórias. Reprimendas com intuito de socializar os detidos. Os conceitos são muito bons, mas ineficazes; e o que era pra ser uma punição ou, então, um centro ressocializador, torna-se um antro de formação de criminosos, uma verdadeira escola do crime. E na falha deste, a solução desesperada apresentada varia entre pena perpétua e pena de morte, desconstruindo tudo o que nossa Constituição Federal/88 conseguiu levantar.

Verifica-se, assim, que a aplicação das medidas socioeducativas aos adolescentes por punição de seus atos é a melhor solução, já que, ainda em formação psicossocial, deverá ter condições estruturais de planejamento de sua vida futura conforme assegurado pelo SINASE e pelo ECA.

\section{CONCLUSÃO}

Infelizmente, não são nossos ideais que se aplicam em nossa sociedade. Sob essa ótica, enquanto houver desigualdade, fome, miséria, falta de educação (o índice de analfabetismo ainda existe, por mais incrível que isso pareça), não haverá como aplicar outras medidas senão as existentes, pois seria retardar ainda mais o desenvolvimento e progressão das pessoas no meio social.

Entretanto, é notório afirmar que o Estado é incompetente na execução de suas tarefas, não sendo o legislador o falho, ou a lei pronta que deixa a desejar, pois analisado suas intenções, são as melhores. Porém, o responsável pelo sistema precário e revoltante é quem faz uso errado dos instrumentos que estão à disposição, distorcendo os fatos. Falhas existem, mas não são da legislação.

Portanto, conclui-se que a aplicação das medidas socioeducativas não são ineficazes em relação à legislação, mas tornam-se ineficazes em sua aplicação, tendo em vista a cultura, existente em nosso País, que ainda equipara o adolescente infrator ao sentenciado (maiores de 18 anos) e que anseia a punição mais severa, sem pensar no objetivo das medidas socioeducativas, que é a reinserção social e não a punibilidade, que é a manutenção dos vínculos familiares do adolescente, que é a reinserção social e não a punibilidade, que é a manutenção dos vínculos familiares do adolescente infrator e não sua exclusão, e, enfim, que é o fortalecimento social em razão do meio em que convive e não sua degradação moral.

\section{REFERÊNCIAS}

BRASIL. Ministério da Educação e Cultura, Assessoria de Comunicação Social.Estatuto da Criança e do Adolescente (ECA). Brasília, 2004.

\footnotetext{
${ }^{1}$ Pedagogo, Consultor da UNICEF, ex-presidente da CBIA

${ }^{2}$ Discurso proferido no lançamento do CD-ROM ‘Direitos da Criança e do Adolescente, em Brasília, em iniciativa conjunta da UNICEF, Fundação Banco do Brasil e 'AJURIS'
} 
BRASIL. Secretaria Especial dos Direitos Humanos, Conselho Nacional dos Direitos da Criança e do Adolescente. Diretrizes Nacionais para a política de atenção integral à infância e a adolescência. Brasil, 2005.

CEARÁ, Assembleia legislativa. Medidas Sócio-educativas - para jovens em situação de risco: Prevenção, Aplicação e Eficácia- Instituto de Estudos e Pesquisa sobre o desenvolvimento do Estado do ceará - INESP: Fortaleza: 2007.

CONSULEX, Revista Jurídica $n^{\circ}$ 193, 2005.

COSTA, Antônio Carlos Gomes da. POR UMA PEDAGOGIA DA ESPERANÇA: Centro Brasileiro para a Infância e Adolescência: Ministério da Ação Social, 1991.

BRASIL. Estatuto da Criança do Adolescente. Lei no 8.069 de 13 de Julho de 1990. Dispõe sobre o Estatuto da Criança e do Adolescente e dá outras providências.Brasília, DF, 1990.

FUNDAÇÃO CASA. Histórico do Atendimento das Medidas Socioeducativas em Meio Aberto. 2005.

GIL, A. C. Métodos e técnicas de pesquisa social. 6. ed. São Paulo: Atlas, 2008.

HENRIQUES, Isabella; HARTUNG, Pedro. O Direito novo do art. 227. Disponível em: $<$ http://www.migalhas.com.br/dePeso/16,MI191102,91041-O+Direito+novo+do+art+227>. Acesso em 10 set. 2016.

LAKATOS, Eva Maria; MARCONI, Marina de Andrade. Fundamentos de metodologia científica. São Paulo: Atlas, 1985

LIBERATI, Wilson Donizeti. Comentários ao Estatuto da Criança e do Adolescente. 5a ed. - São Paulo: Malheiros Editores, 2000.

MARX, Karl; ENGELS, Friedrich. A Ideologia Alemã. São Paulo: Bomtempo, 2007.

MATRACA, Agência. Guia para jornalistas sobre medidas socioeducativas. Disponível em: https://issuu.com/mauricioaraya/docs/guia_sobre_medidas_socioeducativas, acesso em 15 Set. 2016.

PIMENTEL, Manoel Pedro. O Crime e a pena na atualidade. Imprensa: São Paulo, Revista dos Tribunais, 1983.

SECRETARIA ESPECIAL DE DIREITOS HUMANOS. Sistema Nacional de Atendimento Socioeducativo (SINASE). Disponível em: http://www.sdh.gov.br/assuntos/criancas-eadolescentes/programas/sistema-nacional-de-medidas-socioeducativas/sistema-nacional-deatendimento-socioeducativo-sinase-1>. Acesso em 10 ago. 2016.

VARELLA, Drauzio. Redução da maioridade penal. Disponível em: <https://www.youtube.com/watch?v=BmpWjuXtVZA>. Acesso em 08 set. 2016. RIO GRANDE DO SUL, MP. Infância, juventude educação. Disponível em: http://www.mprs.mp.br/infancia/doutrina/id158.htm?impressao=1\&. Acesso em 10 Set. 2016 